This item was submitted to Loughborough's Research Repository by the author.

Items in Figshare are protected by copyright, with all rights reserved, unless otherwise indicated.

\title{
Modeling overland flow and soil erosion on nonuniform hillslopes: a finite volume scheme.
}

PLEASE CITE THE PUBLISHED VERSION

PUBLISHER

(C) American Geophysical Union (AGU)

VERSION

AM (Accepted Manuscript)

LICENCE

CC BY-NC-ND 4.0

\section{REPOSITORY RECORD}

Heng, B.C. Peter, Graham C. Sander, and Cecil F. Scott. 2019. "Modeling Overland Flow and Soil Erosion on Nonuniform Hillslopes: A Finite Volume Scheme.”. figshare. https://hdl.handle.net/2134/4922. 
This item was submitted to Loughborough's Institutional Repository (https://dspace.lboro.ac.uk/) by the author and is made available under the following Creative Commons Licence conditions.

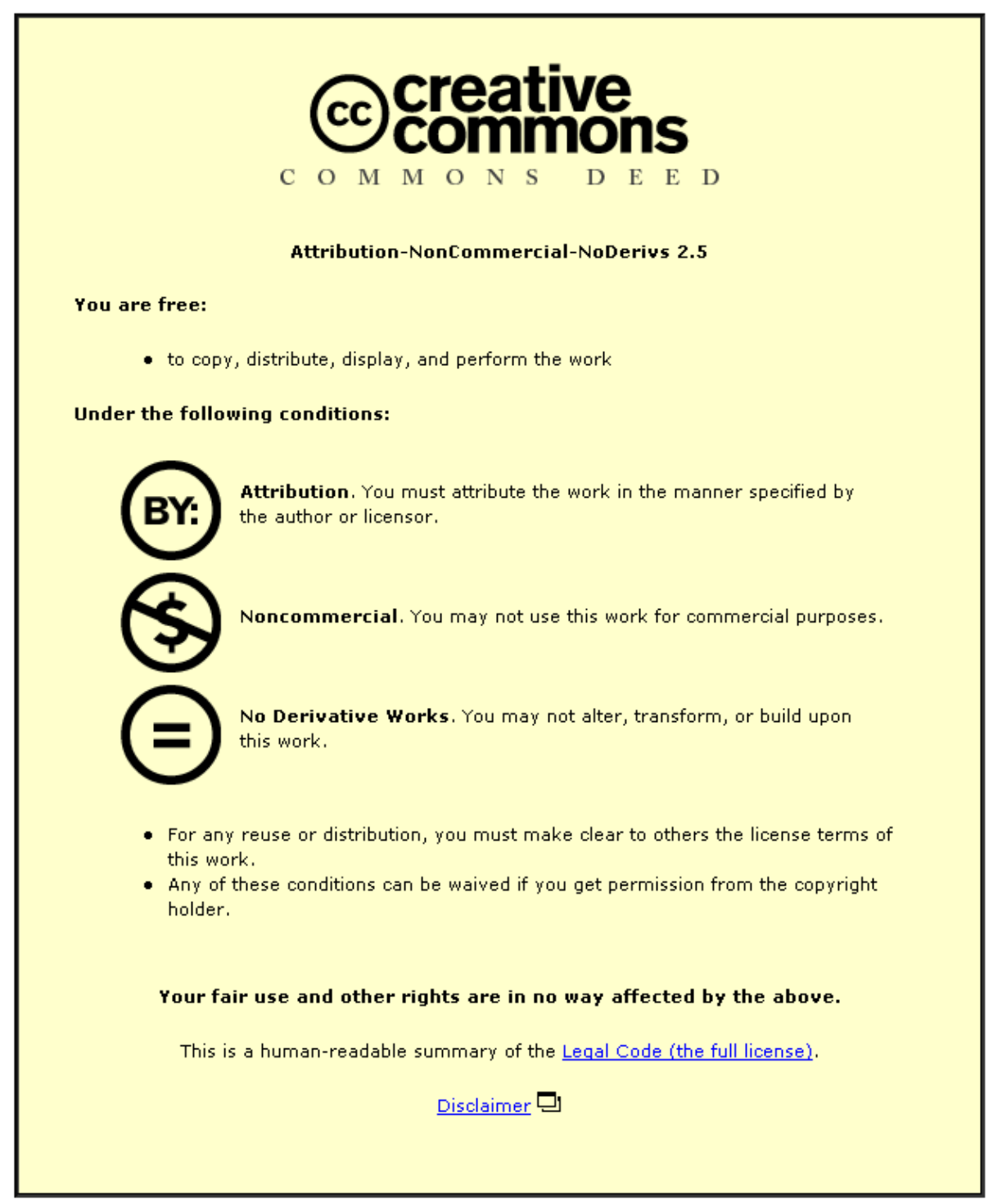

For the full text of this licence, please go to: http://creativecommons.org/licenses/by-nc-nd/2.5/ 


\title{
Modeling Overland Flow and Soil Erosion on Non-Uniform Hillslopes: A Finite Volume Scheme
}

\author{
B. C. Peter Heng \\ Department of Civil and Building Engineering, Loughborough University, UK \\ Graham C. Sander Cecil F. Scott
}

June 25, 2009

\begin{abstract}
This paper presents a finite volume scheme for coupling the St. Venant equations with the multiparticle size class Hairsine-Rose soil erosion model. A well-balanced MUSCL-Hancock scheme is proposed to minimize spurious waves in the solution arising from an imbalance between the flux gradient and the source terms in the momentum equation. Additional criteria for numerical stability when dealing with very shallow flows and wet-dry fronts are highlighted. Numerical tests show that the scheme performs well in terms of accuracy and robustness for both the water and sediment transport equations. The proposed scheme facilitates the application of the Hairsine-Rose model to complex scenarios of soil erosion with concurrent interacting erosion processes over a non-uniform topography.
\end{abstract}

\section{Introduction}

Soil erosion due to rainfall and overland flow is a complex phenomenon. The erodibility of a soil is a function of its particle size distribution, cohesiveness, resistance to aggregate breakdown, antecedent moisture conditions, and soil texture. External factors include rainfall intensity, topography, vegetative cover, slope angle and length. These factors and their interactions can potentially be captured in a model founded on the physical laws governing erosion processes. Hairsine and Rose (Hairsine and Rose, 1991, 1992a,b) developed one such model that has since been applied successfully to various scenarios of soil erosion (Sander et al., 1996; Hairsine et al., 1999; Beuselinck et al., 2002; Rose et al., 2003; Hogarth et al., 2004a; Van Oost et al., 2004; Rose et al., 2007; Sander et al., 2007a). The Hairsine-Rose (H-R) model considers erosion and deposition processes separately, accounts for size-selective sediment transport, and recognizes the development of a deposited layer with different properties from the underlying parent soil. These features together facilitate the modeling of complex evolving scenarios of soil erosion.

As shown in some of the above-cited papers (also, Parlange et al., 1999; Hairsine et al., 2002; Sander et al., 2002; Meerveld et al., 2008), the H-R model can be solved analytically for simple scenarios and with appropriate assumptions. Numerical methods would have to be used for more complex problems involving multiple concurrent erosion processes, non-uniform topography, etc. We present a finite volume scheme in this paper for the solution of the one-dimensional H-R model coupled with the full St. Venant equations. Particular attention is given to developing a well-balanced scheme for the solution of the St. Venant equations to minimize the errors in discharge (leading to errors in erosion rates) that can arise due to varying topography. Related works include Nord and Esteves (2005); Simpson and Castelltort (2006); Murillo et al. (2008) using different (notably, single-class) soil erosion models. Both Nord and Esteves (2005) and Murillo et al. (2008) noted the need to use better models in future work. Our work represents a step in that direction.

The outline of the paper is as follows. A brief description of the governing equations is given in the next section. This is followed by details of the numerical implementation in Section 3. We then verify the implementation with respect to the hydraulics component as well as the full erosion model against benchmark tests in the literature. 


\section{Governing Equations}

The one-dimensional H-R equations for sediment size class $i$ are,

$$
\begin{aligned}
\frac{\partial\left(h c_{i}\right)}{\partial t}+\frac{\partial\left(q c_{i}\right)}{\partial x} & =e_{i}+e_{r i}+r_{i}+r_{r i}-d_{i}, \\
\frac{\partial m_{i}}{\partial t} & =d_{i}-e_{r i}-r_{r i},
\end{aligned}
$$

where $x$ is horizontal distance (approximately equal to distance downslope for small gradients), $h$ is flow depth, $q$ is unit discharge, $c_{i}$ is sediment concentration in mass per unit volume, and $m_{i}$ is the deposited sediment mass per unit area. The source terms $e_{i}, e_{r i}, r_{i}, r_{r i}$, and $d_{i}$ are, respectively, detachment and re-detachment rates due to rainfall, entrainment and re-entrainment rates due to runoff, and the rate of deposition with units of mass per unit area per unit time.

The rainfall-related erosion rates are evaluated as

$$
\begin{aligned}
e_{i} & =(1-H) p_{i} a P \\
e_{r i} & =H \frac{m_{i}}{m_{t}} a_{d} P
\end{aligned}
$$

where $P$ is rainfall intensity, $a$ is the detachability of undisturbed soil, and $a_{d}$ the detachability of deposited sediment, in mass per unit area per unit rainfall, $p_{i}$ is the proportion of class $i$ sediment in the original soil (Sander et al., 2007b), $m_{t}=\sum m_{i}$ is the total deposited sediment mass per unit area, $H=\min \left(m_{t} / m_{t}^{*}, 1\right)$ represents the degree of shielding provided by the deposited sediment, and $m_{t}^{*}$ is the mass of deposited sediment required to shield the original soil completely.

Runoff entrainment and re-entrainment rates are evaluated as

$$
\begin{aligned}
r_{i} & =(1-H) p_{i} \frac{F\left(\Omega-\Omega_{c r}\right)}{J}, \\
r_{r i} & =H \frac{m_{i}}{m_{t}} \frac{F\left(\Omega-\Omega_{c r}\right)}{\frac{\rho_{s}-\rho_{w}}{\rho_{s}} g h}
\end{aligned}
$$

respectively, where $\Omega$ is stream power and $\Omega_{c r}$ the critical stream power at incipient motion, $F$ is the fraction of excess stream power effective in entrainment and re-entrainment, $J$ is the energy required per unit mass of sediment for entrainment, $g$ is the acceleration due to gravity, $\rho_{s}$ is sediment density and $\rho_{w}$ the density of water. Flow stream power is determined using the equation $\Omega=\rho_{w} g S_{f} q$, where $S_{f}=n^{2} q^{2} h^{-10 / 3}$ is friction slope and $n$ is Manning's roughness coefficient. The rate of deposition for sediment class $i$ is $d_{i}=v_{i} c_{i}$, where $v_{i}$ is the settling velocity of particles in that class.

The St. Venant equations with lateral inflow due to rainfall are:

$$
\begin{aligned}
\frac{\partial h}{\partial t}+\frac{\partial q}{\partial x} & =P \\
\frac{\partial q}{\partial t}+\frac{\partial}{\partial x}\left(\frac{q^{2}}{h}+\frac{1}{2} g h^{2}\right) & =-g h\left(S_{0}+S_{f}\right)-P u
\end{aligned}
$$

where $S_{0}=\mathrm{d} z / \mathrm{d} x$ is bed slope, $z$ is bed elevation (positive upwards), $u$ is flow velocity, and the $x$ component of raindrop velocity is assumed negligible.

The coupled system of governing equations is therefore

$$
\begin{aligned}
\frac{\partial}{\partial t} \mathbf{U}+\frac{\partial}{\partial x} \mathbf{F} & =\mathbf{S} \\
\frac{\partial}{\partial t} \mathbf{M} & =\mathbf{D},
\end{aligned}
$$


where, with $I$ sediment classes,

$$
\begin{aligned}
& \mathbf{U}=\left[\begin{array}{c}
h \\
q \\
h c_{1} \\
\vdots \\
h c_{I}
\end{array}\right], \mathbf{F}=\left[\begin{array}{c}
q \\
\frac{q^{2}}{h}+\frac{1}{2} g h^{2} \\
q c_{1} \\
\vdots \\
q c_{I}
\end{array}\right] \\
& \mathbf{S}=\left[\begin{array}{c}
P \\
-g h\left(S_{0}+S_{f}\right)-P u \\
e_{1}+e_{r 1}+r_{1}+r_{r 1}-d_{1} \\
\vdots \\
e_{I}+e_{r I}+r_{I}+r_{r I}-d_{I}
\end{array}\right] \\
& \mathbf{M}=\left[\begin{array}{c}
m_{1} \\
\vdots \\
m_{I}
\end{array}\right], \mathbf{D}=\left[\begin{array}{c}
d_{1}-e_{r 1}-r_{r 1} \\
\vdots \\
d_{I}-e_{r I}-r_{r I}
\end{array}\right] \text {. }
\end{aligned}
$$

The system of equations (1) can be written in quasilinear form

$$
\frac{\partial}{\partial t} \mathbf{U}+\mathbf{A} \frac{\partial}{\partial x} \mathbf{U}=\mathbf{S}
$$

where

$$
\mathbf{A}=\frac{\partial \mathbf{F}}{\partial \mathbf{U}}=\left[\begin{array}{ccccc}
0 & 1 & 0 & \cdots & 0 \\
g h-u^{2} & 2 u & 0 & \cdots & 0 \\
-u c_{1} & c_{1} & u & \cdots & 0 \\
\vdots & \vdots & \vdots & \ddots & \vdots \\
-u c_{I} & c_{I} & 0 & \cdots & u
\end{array}\right]
$$

The eigenvalues of $\mathbf{A}$ (corresponding to the wave speeds of the system) are $\lambda_{1}=u-\sqrt{g h}, \lambda_{2}=$ $u+\sqrt{g h}$, and $\lambda_{3, \ldots, I+2}=u$ (with an algebraic multiplicity equal to the number of sediment classes). The corresponding eigenvectors (waves) are

$$
\mathbf{r}_{1}=\left[\begin{array}{c}
1 \\
\lambda_{1} \\
c_{1} \\
\vdots \\
c_{I}
\end{array}\right], \mathbf{r}_{2}=\left[\begin{array}{c}
1 \\
\lambda_{2} \\
c_{1} \\
\vdots \\
c_{I}
\end{array}\right], \mathbf{r}_{3}=\left[\begin{array}{c}
0 \\
0 \\
1 \\
\vdots \\
0
\end{array}\right], \ldots, \mathbf{r}_{I+2}=\left[\begin{array}{c}
0 \\
0 \\
0 \\
\vdots \\
1
\end{array}\right]
$$

The quasilinear form is the basis for linearized approximate Riemann solvers commonly used in numerical solutions of hyperbolic equations.

\section{Numerical Solution}

We adopt a cell-centered discretization of bed elevation as well as state variables. Defining $z$ at cell centers rather than at cell interfaces is convenient for mobile-bed applications as erosion and deposition rates are computed at cell centers.

Given initial values and boundary conditions, we obtain the solution at the next time step explicitly using the MUSCL-Hancock method (van Leer, 1984), which can be outlined as follows:

1. Piecewise-linear state reconstruction at $t^{n}$ with an appropriate slope limiter.

2. Predictor step, advancing to $t^{n+\frac{1}{2}}$.

3. Solution of the Riemann problem at each cell interface.

4. Corrector step to obtain solution at $t^{n+1}$. 
The numerical problems associated with solving the St. Venant equations with varying topography are well known. Spurious waves can arise due to an imbalance between the flux-gradient and the source terms in the momentum equation, and various solutions have been proposed (e.g., Bermudez and Vazquez, 1994; LeVeque, 1998; Hubbard and Garcia-Navarro, 2000; Zhou et al., 2001; Li and Chen, 2006; Noelle et al., 2007; George, 2008).

Within the framework of the MUSCL-Hancock approach, we introduce two modifications to preserve the flux-source balance in steady flow. First, we impose conditions on state reconstruction to ensure steady state is preserved in the predictor step. Second, following Hubbard and Garcia-Navarro (2000), source term integrals at cell interfaces are split into left- and right-going components for updating state variables in adjacent cells.

The numerical scheme is discussed in greater detail in the following subsections.

\subsection{State Reconstruction and Predictor Steps}

The MUSCL approach reconstructs cell state in a piecewise-linear manner to achieve second-order accuracy in space (van Leer, 1979). Slope limiters are used in this step to preserve monotonicity. We have found the van Leer limiter to be robust while not excessively diffusive. We follow Quirk (1994) in applying the slope limiter to wave strengths rather than elements of the state gradient vector.

The state reconstruction step gives, for cell $j, \mathbf{U}_{j+\frac{1}{2}, L}^{n}$ and $\mathbf{U}_{j-\frac{1}{2}, R}^{n}$, the states left of $x_{j+\frac{1}{2}}$ and right of $x_{j-\frac{1}{2}}$ respectively. The predictor equation then advances the solution by half a time step, giving

$$
\mathbf{U}_{j}^{n+\frac{1}{2}}=\mathbf{U}_{j}^{n}-\frac{\Delta t}{2 \Delta x_{j}}\left(\mathbf{F}_{j+\frac{1}{2}, L}^{n}-\mathbf{F}_{j-\frac{1}{2}, R}^{n}\right)+\frac{\Delta t}{2} \mathbf{S}_{j}^{n},
$$

with the state gradient unchanged over the half step, that is,

$$
\mathbf{U}_{j+\frac{1}{2}, L}^{n+\frac{1}{2}}-\mathbf{U}_{j-\frac{1}{2}, R}^{n+\frac{1}{2}}=\mathbf{U}_{j+\frac{1}{2}, L}^{n}-\mathbf{U}_{j-\frac{1}{2}, R}^{n}=\Delta \mathbf{U}_{j} .
$$

For steady state, we require $\mathbf{U}_{j}^{n+\frac{1}{2}}=\mathbf{U}_{j}^{n}$ or $\mathbf{F}_{j+\frac{1}{2}, L}^{n}-\mathbf{F}_{j-\frac{1}{2}, R}^{n}=\Delta x_{j} \mathbf{S}_{j}^{n}$. We consider first quiescent conditions (a special case of steady-state conditions), where $q_{j}=0$ and $\eta_{j}=h_{j}+z_{j}=\eta_{0}$, a constant, for all $j$. The gradient in $h$ between $x_{j-1}$ and $x_{j}$ is

$$
\left(\frac{\Delta h}{\Delta x}\right)_{j-\frac{1}{2}}=\frac{h_{j}-h_{j-1}}{x_{j}-x_{j-1}}=\frac{-z_{j}+z_{j-1}}{x_{j}-x_{j-1}}=-\left(\frac{\Delta z}{\Delta x}\right)_{j-\frac{1}{2}}
$$

and, between $x_{j}$ and $x_{j+1}$,

$$
\left(\frac{\Delta h}{\Delta x}\right)_{j+\frac{1}{2}}=-\left(\frac{\Delta z}{\Delta x}\right)_{j+\frac{1}{2}} .
$$

The slope limiter algorithm gives

$$
\frac{\Delta h_{j}}{\Delta x_{j}}=\phi_{A}\left(\theta_{j}^{h}\right)\left(\frac{\Delta h}{\Delta x}\right)_{j+\frac{1}{2}}=-\phi_{A}\left(\theta_{j}^{h}\right)\left(\frac{\Delta z}{\Delta x}\right)_{j+\frac{1}{2}},
$$

where $\phi_{A}(\cdot)$ is an arbitrary limiter function and

$$
\theta_{j}^{h}=\frac{\left(\frac{\Delta h}{\Delta x}\right)_{j-\frac{1}{2}}}{\left(\frac{\Delta h}{\Delta x}\right)_{j+\frac{1}{2}}}=\frac{\left(\frac{\Delta z}{\Delta x}\right)_{j-\frac{1}{2}}}{\left(\frac{\Delta z}{\Delta x}\right)_{j+\frac{1}{2}}}
$$

This gradient in $h$ across cell $j$ results in a momentum flux gradient

$$
\frac{g}{2}\left(\frac{h_{j+\frac{1}{2}, L}^{2}-h_{j-\frac{1}{2}, R}^{2}}{\Delta x_{j}}\right)=-g h_{j} \phi_{A}\left(\theta_{j}^{h}\right)\left(\frac{\Delta z}{\Delta x}\right)_{j+\frac{1}{2}},
$$

which has to be balanced by the source term $-g h_{j} \Delta z_{j} / \Delta x_{j}$ if quiescent conditions are to be preserved in the predictor step. That is, we require

$$
\frac{\Delta z_{j}}{\Delta x_{j}}=\phi_{A}\left(\theta_{j}^{h}\right)\left(\frac{\Delta z}{\Delta x}\right)_{j+\frac{1}{2}},
$$


which implies that $z$ has to be reconstructed with the same limiter function that is used in the reconstruction of $h$. This is the only condition required to preserve quiescent conditions in the predictor step.

Let us now consider steady flow conditions $\left(q_{j}=q_{0}\right.$ for all $\left.j\right)$. Between cells $j$ and $j+1$, steady flow requires

$$
\begin{aligned}
\mathbf{F}_{j+1}-\mathbf{F}_{j} & =\int_{x_{j}}^{x_{j+1}} \mathbf{S} \mathrm{d} x, \text { or } \\
\mathbf{U}_{j+1}-\mathbf{U}_{j} & =\left[\widehat{\mathbf{A}}\left(\mathbf{U}_{j}, \mathbf{U}_{j+1}\right)\right]^{-1} \int_{x_{j}}^{x_{j+1}} \mathbf{S} \mathrm{d} x
\end{aligned}
$$

where $\widehat{\mathbf{A}}(\mathbf{V}, \mathbf{W})$ is Roe's Jacobian evaluated between states $\mathbf{V}$ and $\mathbf{W}$. Similarly, steady flow between cells $j-1$ and $j$ requires

$$
\mathbf{U}_{j}-\mathbf{U}_{j-1}=\left[\widehat{\mathbf{A}}\left(\mathbf{U}_{j-1}, \mathbf{U}_{j}\right)\right]^{-1} \int_{x_{j-1}}^{x_{j}} \mathbf{S} \mathrm{d} x .
$$

Assuming (3) and (4) are satisfied exactly, setting state gradient in cell $j$ as some function of $(\Delta \mathbf{U} / \Delta x)_{j-\frac{1}{2}}$ and $(\Delta \mathbf{U} / \Delta x)_{j+\frac{1}{2}}$ would not in general satisfy

$$
\frac{\Delta \mathbf{U}_{j}}{\Delta x_{j}}=\widehat{\mathbf{A}}_{j}^{-1} \mathbf{S}_{j}
$$

where $\widehat{\mathbf{A}}_{j}=\widehat{\mathbf{A}}\left(\mathbf{U}_{j-\frac{1}{2}, R}, \mathbf{U}_{j+\frac{1}{2}, L}\right)$. Thus the condition for steady flow in cell $j$ is violated. An imbalance between the flux gradient and the source term in the predictor step means $\mathbf{U}_{j}^{n+\frac{1}{2}} \neq \mathbf{U}_{j}^{n}$, with the error propagating into the corrector step. This explains the errors observed by Hubbard and Garcia-Navarro (2000) with their slope-limited scheme.

Solving (5) for the required state gradient across cell $j$ is non-trivial because $\Delta \mathbf{U}_{j}$ appears on both sides of the equation. Consider the frictionless St. Venant equations without rainfall, where

$$
\widehat{\mathbf{A}}=\left[\begin{array}{cc}
0 & 1 \\
-\hat{u}^{2}+g \bar{h} & 2 \hat{u}
\end{array}\right] \text { and } \mathbf{S}=\left[\begin{array}{c}
0 \\
-g h \frac{\Delta z}{\Delta x}
\end{array}\right] .
$$

The steady-state condition (in addition to the trivial $\Delta q_{j}=0$ ) in this case is

$$
\Delta h_{j}=\frac{g h_{j} \Delta z_{j}}{\frac{q^{2}}{h_{j}^{2}-0.25 \Delta h_{j}^{2}}-g h_{j}} .
$$

We can use a rough estimate for $\Delta h_{j}$ on the right to obtain a second approximation on the left. A good initial estimate for $\Delta h_{j}$ is $0.5\left(\eta_{j+1}-\eta_{j-1}\right)-\left(z_{j+\frac{1}{2}, L}-z_{j-\frac{1}{2}, R}\right)$. We have found that a single iteration is sufficient to get a close approximation.

The above adjustment to $\Delta \mathbf{U}_{j}$ is only valid at steady state so a check has to be performed to determine if the flow is steady. Consider a 'control volume' between $x_{j-1}$ and $x_{j+1}$. Then

$$
\frac{\overline{\mathbf{U}}_{j}^{n+1}-\overline{\mathbf{U}}_{j}^{n}}{\Delta t}+\frac{\mathbf{F}\left(\mathbf{U}_{j+1}^{n}\right)-\mathbf{F}\left(\mathbf{U}_{j-1}^{n}\right)}{x_{j+1}-x_{j-1}}=\mathbf{S}\left(\mathbf{U}_{j-1}^{n}, \mathbf{U}_{j+1}^{n}\right),
$$

where $\overline{\mathbf{U}}_{j}=0.5\left(\mathbf{U}_{j+1}+\mathbf{U}_{j-1}\right)$. Near steady state, $\overline{\mathbf{U}}_{j}^{n+1}-\overline{\mathbf{U}}_{j}^{n}$ would be small relative to $\overline{\mathbf{U}}_{j}^{n}$. We therefore check that

$$
\Delta t\left|-\frac{\mathbf{F}\left(\mathbf{U}_{j+1}^{n}\right)-\mathbf{F}\left(\mathbf{U}_{j-1}^{n}\right)}{x_{j+1}-x_{j-1}}+\mathbf{S}\left(\mathbf{U}_{j-1}^{n}, \mathbf{U}_{j+1}^{n}\right)\right| \leq \epsilon \overline{\mathbf{U}}_{j}^{n},
$$

where $\epsilon$ is much smaller than unity, say, 0.001. We adjust the state slope only if the above condition is met for all state variables. 


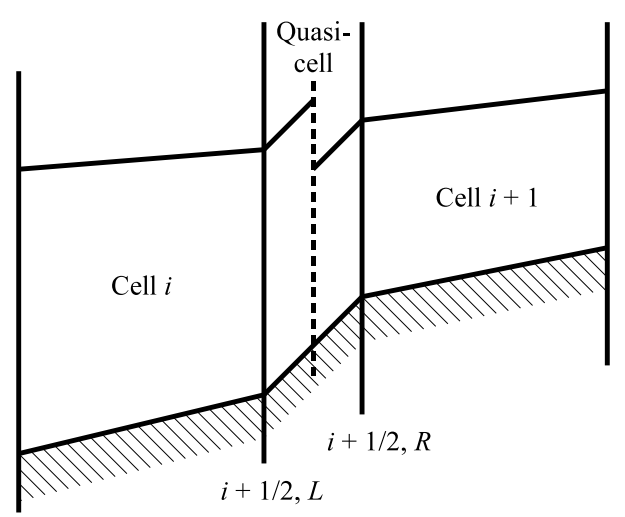

Figure 1: The interface quasi-cell.

\subsection{Solving the Riemann Problem at Cell Interfaces}

The reconstruction step results in discontinuities in $z$ as well as in $\mathbf{U}$ across each cell interface. Suppose there is a quasi-cell at each interface with a linearly-varying $z$ linking the bed elevation on either side (Fig. 1). Extrapolating the states $\mathbf{U}_{j+\frac{1}{2}, L}$ and $\mathbf{U}_{j+\frac{1}{2}, R}$, from the left and right respectively, to the center of the quasi-cell, we end up with a conventional Riemann problem that can be solved using any standard method. We use Roe's solver (Roe, 1981), which gives an approximation to the flux across the interface as

$$
\mathcal{F}=\frac{1}{2}\left(\mathbf{F}_{L}+\mathbf{F}_{R}\right)-\frac{1}{2} \widehat{\mathbf{R}}|\widehat{\boldsymbol{\Lambda}}| \widehat{\mathbf{R}}^{-1}\left(\mathbf{U}_{R}-\mathbf{U}_{L}\right),
$$

where $\widehat{\mathbf{R}} \widehat{\mathbf{\Lambda}} \widehat{\mathbf{R}}^{-1}=\widehat{\mathbf{A}}$ is the approximate Jacobian matrix with primitive variables

$$
\begin{aligned}
\bar{h} & =\frac{h_{L}+h_{R}}{2}, \\
\hat{u} & =\frac{\sqrt{h_{L}} u_{L}+\sqrt{h_{R}} u_{R}}{\sqrt{h_{L}}+\sqrt{h_{R}}}, \\
\hat{c}_{i} & =\frac{\sqrt{h_{L}} c_{i, L}+\sqrt{h_{R}} c_{i, R}}{\sqrt{h_{L}}+\sqrt{h_{R}}} .
\end{aligned}
$$

The subscript $j+0.5$ is implicit in the above equations. The entropy correction function proposed by Harten and Hyman (1983) is used to eliminate entropy-violating discontinuities where there is a transonic rarefaction.

Following Hubbard and Garcia-Navarro (2000), the quasi-cell source term integral $\overline{\overline{\mathbf{S}}}=\int_{x_{L}}^{x_{R}} \mathbf{S} \mathrm{d} x$ is split into left- and right-going components:

$$
\overline{\overline{\mathbf{S}}}^{ \pm}=\frac{1}{2}\left[\mathbf{I} \pm \mathbf{R} \operatorname{sgn}(\boldsymbol{\Lambda}) \mathbf{R}^{-1}\right] \overline{\overline{\mathbf{S}}}
$$

where the left-going (right-going) component is denoted by the negative (positive) superscript and

$$
\operatorname{sgn}(\boldsymbol{\Lambda})=\left[\begin{array}{llll}
\operatorname{sgn}\left(\lambda_{1}\right) & & & \\
& \operatorname{sgn}\left(\lambda_{2}\right) & & \\
& & \ddots & \\
& & & \operatorname{sgn}\left(\lambda_{I+2}\right)
\end{array}\right]
$$

With reference to our system, the integral of the source term due to bed slope in the quasi-cell is $-g \bar{h}\left(z_{R}-z_{L}\right)$, where $\bar{h}=0.5\left(h_{L}+h_{R}\right)$. Physically, this may be interpreted as the rate of change of momentum across the interface due to the step in bed elevation. Note that this is the only source term that needs to be considered in the quasi-cell: all other source term integrals vanish as $\left(x_{R}-x_{L}\right) \rightarrow 0$. 


\subsection{State Update}

The corrector equation advances the solution by a full time step based on the fluxes and source terms at the half step:

$$
\begin{aligned}
\mathbf{U}_{j}^{n+1}= & \mathbf{U}_{j}^{n}-\frac{\Delta t}{\Delta x_{j}}\left(\mathcal{F}_{j+\frac{1}{2}}^{n+\frac{1}{2}}-\mathcal{F}_{j-\frac{1}{2}}^{n+\frac{1}{2}}\right) \\
& +\frac{\Delta t}{\Delta x_{j}}\left(\left[\overline{\overline{\mathbf{S}}}_{j-\frac{1}{2}}^{n+\frac{1}{2}}\right]^{+}+\left[\overline{\mathbf{S}}_{j+\frac{1}{2}}^{n+\frac{1}{2}}\right]^{-}\right)+\Delta t \mathbf{S}_{j}^{n+\frac{1}{2}}
\end{aligned}
$$

The justification for this formulation is given in Hubbard and Garcia-Navarro (2000), and it can be shown that quiescent conditions are exactly preserved with this equation. To give the physical sense, we reason as follows. Quiescent state reconstruction (Section 3.1) results in a constant surface level across the whole domain. The predictor step preserves this. In the corrector step, the momentum flux gradient across each cell is balanced exactly by the bed slope source term and the flux difference across each interface by the quasi-cell source integral. Thus $\mathbf{U}_{j}^{n+1}=\mathbf{U}_{j}^{n}$ for all $j$ and quiescent conditions are preserved.

With steady flow, the situation is less intuitive. Suppose (2) is satisfied at $t^{n}$. If we then set state gradients in cells $j$ and $j+1$ so that (5) is satisfied in both cells, we have $\Delta \mathbf{F}_{j}=\int \mathbf{S}_{j} \mathrm{~d} x$ and $\Delta \mathbf{F}_{j+1}=\int \mathbf{S}_{j+1} \mathrm{~d} x$. Since

$$
\begin{aligned}
\int_{x_{j}}^{x_{j+1}} \mathbf{S} \mathrm{d} x & =\int_{x_{j}}^{x_{j+\frac{1}{2}, L}} \mathbf{S} \mathrm{d} x+\overline{\overline{\mathbf{S}}}_{j+\frac{1}{2}}+\int_{x_{j+\frac{1}{2}, R}}^{x_{j+1}} \mathbf{S} \mathrm{d} x \\
& =\frac{\Delta \mathbf{F}_{j}}{2}+\overline{\overline{\mathbf{S}}}_{j+\frac{1}{2}}+\frac{\Delta \mathbf{F}_{j+1}}{2},
\end{aligned}
$$

we can rewrite $(2)$ as

$$
\left(\mathbf{F}_{j+1}-\frac{\Delta \mathbf{F}_{j+1}}{2}\right)-\left(\mathbf{F}_{j}+\frac{\Delta \mathbf{F}_{j}}{2}\right)=\int_{x_{j+\frac{1}{2}, L}}^{x_{j+\frac{1}{2}, R}} \mathbf{S} \mathrm{d} x .
$$

The left-hand side is only approximately equal to $\mathbf{F}_{j+\frac{1}{2}, R}-\mathbf{F}_{j+\frac{1}{2}, L}$ because, while $\mathbf{U}$ is piecewise linear within cells, $\mathbf{F}$ is a nonlinear function of $\mathbf{U}$. Thus the steady flow condition across $x_{j+\frac{1}{2}}$ is only approximately satisfied. It can be shown that the error is $O\left(\Delta \mathbf{U}_{j}^{2}\right)$ and, as such, is negligible in many cases.

The deposited masses are simply updated via

$$
\mathbf{M}_{j}^{n+1}=\mathbf{M}_{j}^{n}+\Delta t \mathbf{D}_{j}^{n+\frac{1}{2}}
$$

\subsection{Critical Time Step}

The CFL condition for stability (Courant et al., 1967) requires, for the advection problem,

$$
\frac{\Delta t}{\Delta x} \max _{p}\left|\lambda_{p}\right| \leq 1
$$

In the present work, it is only necessary to consider $\lambda_{1}$ and $\lambda_{2}$ : the other wave speed lies between these two.

Besides the CFL condition, there is another restriction on time step due to the H-R equations. Consider the suspended sediment mass balance for class $i$ sediment. Clearly, a negative $h c_{i}$ does not make sense. Hence we require, based on the corrector equation,

$$
\Delta t \leq \frac{\left(h c_{i}\right)_{j}^{n}}{\frac{1}{\Delta x_{j}}\left(\mathcal{F}_{j+\frac{1}{2}}^{n+\frac{1}{2}}-\mathcal{F}_{j-\frac{1}{2}}^{n+\frac{1}{2}}\right)_{h c_{i}}-\left(\mathbf{S}_{j}^{n+\frac{1}{2}}\right)_{h c_{i}}},
$$

where $\mathbf{S}_{h c_{i}}=e_{i}+e_{r i}+r_{i}+r_{r i}-d_{i}$. We cannot obtain the upper bound on $\Delta t$ directly using the above because the denominator depends on the state at $t^{n}+0.5 \Delta t$. A rough estimate can be obtained by 
ignoring the flux gradient and the erosion source terms and using the approximation $d_{i}^{n+\frac{1}{2}} \approx d_{i}^{n}$, which leaves us with

$$
\Delta t \leq\left(\frac{h c_{i}}{d_{i}}\right)_{j}^{n}=\frac{h_{j}^{n}}{v_{i}} .
$$

Physically, this criterion states that the amount of sediment deposited over a time increment cannot be greater than that in the flow. The upper bound on $\Delta t$ is determined by the ratio of the minimum flow depth over the domain to the settling velocity of the largest particles. This could be updated at every step or determined a priori for simpler problems where an estimated flow depth is available. Since the problems we are interested in are characterized by very small flow depths $(\sim 5 \mathrm{~mm})$, the time step will often be governed by this criterion.

\section{Verification}

The numerical scheme described in the previous section was verified against a number of benchmarks. The first two tests show that accurate solutions (relative to comparable schemes in the literature) to the St. Venant equations with varying topography can be obtained. The next two demonstrate the robustness of the scheme in handling wetting and drying scenarios with and without friction. We compare the solution of the St. Venant equations with the kinematic wave approximation in Section 4.5. Finally, we verify numerical solutions of the full system (including the H-R equations) against solutions in the literature for two different scenarios: rainfall-driven soil erosion and net deposition in overland flow. We used a Courant number of 0.8 for all tests except the last two, where the critical time step was governed by $(6)$.

\subsection{Steady Flow over a Bump}

The benchmark tests associated with steady flow over a bump (Goutal and Maurel, 1997) have been widely used (e.g., Zhou et al., 2001; Li and Chen, 2006; Noelle et al., 2007; George, 2008). The availability of exact analytical solutions make them ideal independent checks for numerical schemes. In particular, since $q$ is spatially uniform at steady state, any deviation from the exact solution due to the flux-source imbalance is immediately evident.

The benchmark problem consists of a $25 \mathrm{~m}$ long frictionless channel with bed topography defined by

$$
z(x)=\left\{\begin{array}{ll}
0.2-0.05(x-10)^{2} & \text { for } 8<x<12 \\
0 & \text { otherwise }
\end{array} .\right.
$$

Different steady-state solutions are obtained by varying the boundary conditions. To highlight the importance of balancing the flux gradient and the source term in the predictor step, we compare the solutions obtained with and without slope adjustment. The same mesh, with $\Delta x=0.25 \mathrm{~m}$, was used throughout.

Figures 2 to 4 compares the numerical and analytical solutions for three different steady-state scenarios. The water surface level is resolved very well in each case. The benefit of slope adjustment in the predictor step is evident from the discharge plots. The $L_{1}$ errors in $q$ are shown in Table 1 . The solution close to the hydraulic jump in the last scenario can be improved by shifting the domain such that the jump is located exactly at a cell interface (Noelle et al., 2007). This fix is generally not practicable since we do not know the position of the hydraulic jump a priori. George (2008) chose to ignore the error in the cell containing the jump, arguing that the averaged flow depth in that cell does not correctly reflect the presence of a discontinuity anyway.

\subsection{Quasi-Steady Flow}

We use this test case, first proposed by LeVeque (1998) and since used by others (e.g., Hubbard and Garcia-Navarro, 2000; Zhou et al., 2001; Li and Chen, 2006), to show that the modeling of unsteady flow is not adversely affected by the adjustment of the state slope where steady flow prevails.

The bed topography is described by

$$
z(x)=\left\{\begin{array}{ll}
0.25\{\cos [10 \pi(x-0.5)]+1\} & \text { for } 0.4<x<0.6 \\
0 & \text { otherwise }
\end{array} .\right.
$$




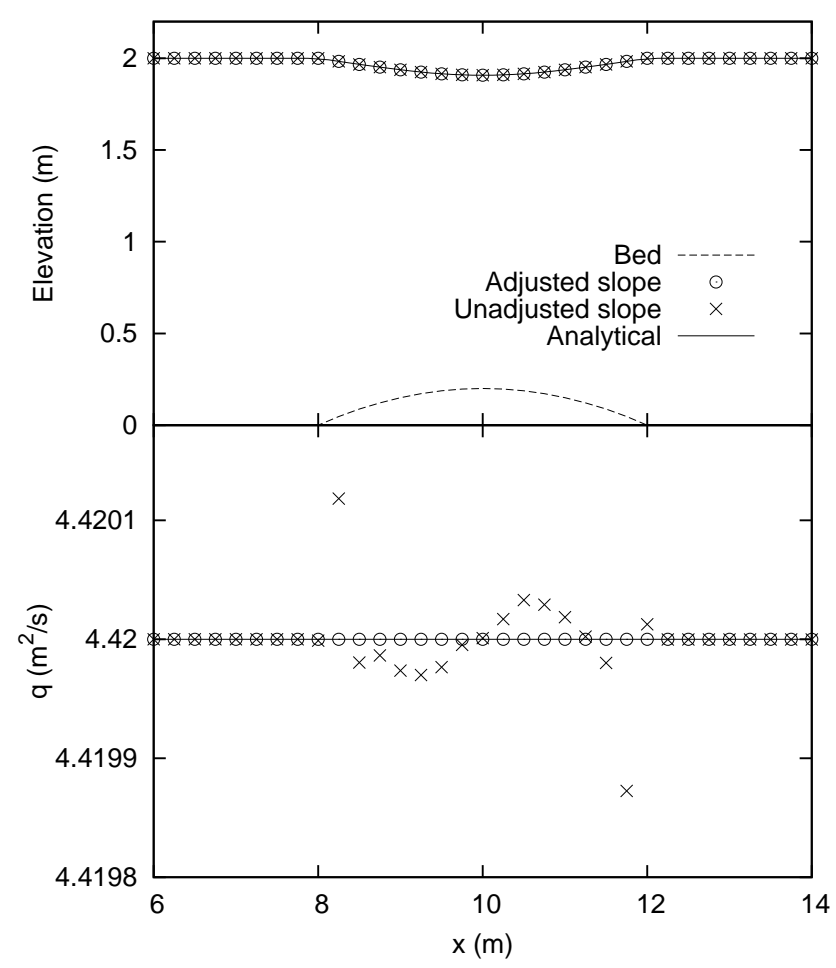

Figure 2: Numerical and analytical solutions of the St. Venant equations for steady subcritical flow over a bump ( $q=4.42 \mathrm{~m}^{2} \mathrm{~s}^{-1}$ upstream and $h=2 \mathrm{~m}$ downstream). The discharge values obtained with slope adjustment in the predictor step $(\circ)$ is clearly more accurate than those obtained without slope adjustment $(x)$.

Table 1: $L_{1}$ errors in $q$ for the steady flow over bump problems.

\begin{tabular}{lcc}
\hline Class & $\begin{array}{c}\text { Adjusted slope } \\
\text { Settling velocity } \\
\left(\mathrm{mm} \mathrm{s}^{-1}\right)\end{array}$ & Unadjusted slope \\
\hline Subcritical flow & $2.1 \times 10^{-10}$ & $1.1 \times 10^{-6}$ \\
Transcritical flow & $1.3 \times 10^{-7}$ & $3.2 \times 10^{-5}$ \\
Transcritical flow with shock & $0.94 \times 10^{-3}$ & $1.1 \times 10^{-3}$ \\
\hline
\end{tabular}




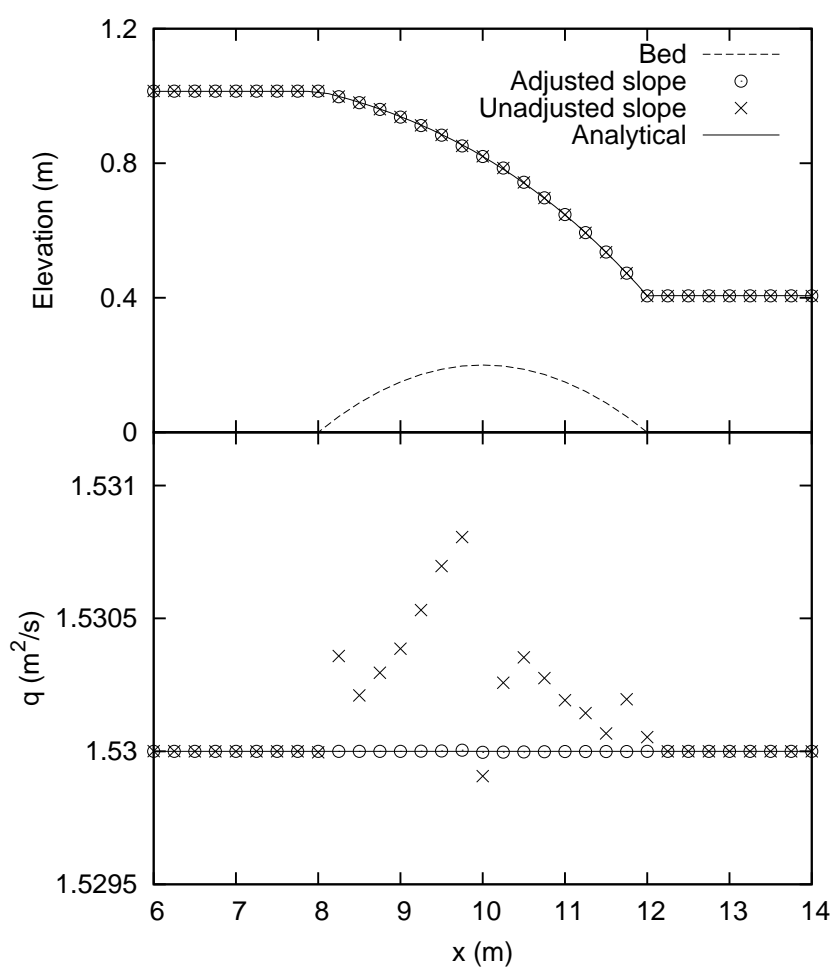

Figure 3: Numerical and analytical solutions of the St. Venant equations for steady transcritical flow over a bump ( $q=1.53 \mathrm{~m}^{2} \mathrm{~s}^{-1}$ upstream). The discharge values obtained with slope adjustment in the predictor step $(\circ)$ is clearly more accurate than those obtained without slope adjustment $(\times)$. 


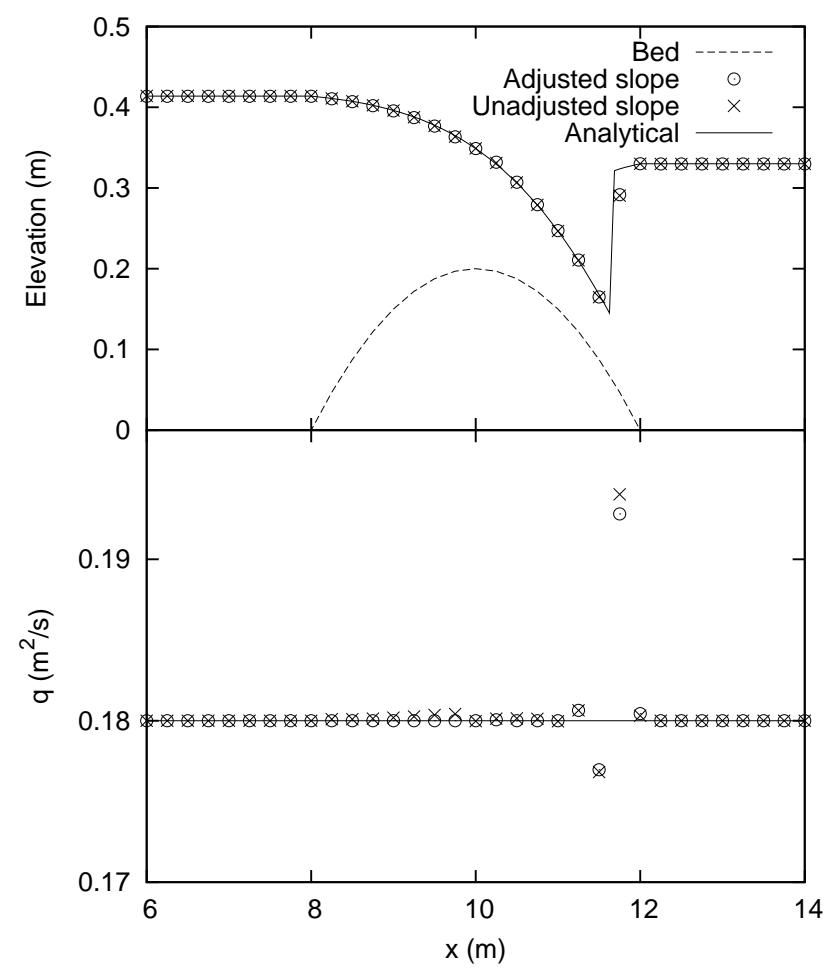

Figure 4: Numerical and analytical solutions of the St. Venant equations for steady transcritical flow with shock ( $q=0.18 \mathrm{~m}^{2} \mathrm{~s}^{-1}$ upstream and $h=0.33 \mathrm{~m}$ downstream). There is noticeable improvement in the accuracy of the discharge values in the region $8<x<10$. 


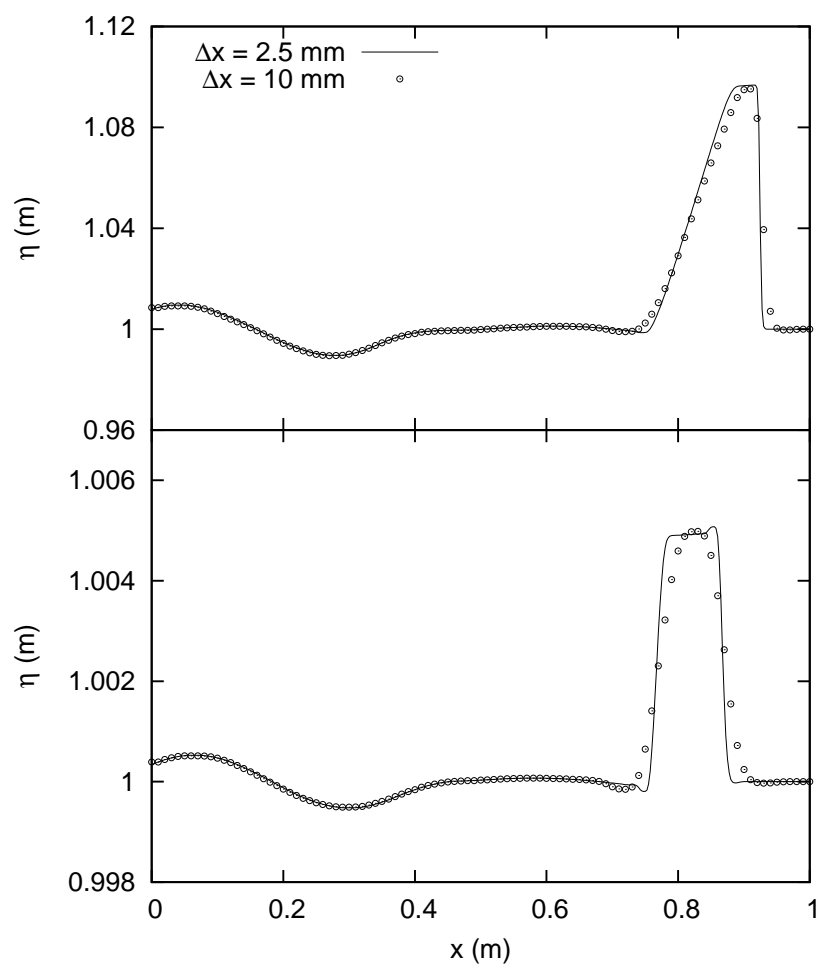

Figure 5: Numerical solutions to the quasi-steady problem (LeVeque, 1998) for two values of $\epsilon$, the initial perturbation of the water surface: $\epsilon=0.2$ (top) and $\epsilon=0.01$ (bottom), at $t=0.7 \mathrm{~s}$.

The initial conditions are $q=0$ and

$$
\eta(x)=\left\{\begin{array}{ll}
1+\epsilon & \text { for } 0.1<x<0.2 \\
1 & \text { otherwise }
\end{array},\right.
$$

where $\epsilon$ is a small perturbation of the water surface. The acceleration due to gravity is $g=1 \mathrm{~m} \mathrm{~s}^{-2}$, as used by LeVeque (1998).

The numerical solutions for initial perturbations of $0.2 \mathrm{~m}$ and $0.01 \mathrm{~m}$, obtained using two mesh resolutions, are shown in Fig. 5 for the time instant $t=0.7 \mathrm{~s}$. The steady-state checks proposed in Section 3.1 effectively exclude unsteady flow (even if only slightly) from being subjected to state slope adjustment in the predictor step. Hence the high-resolution shock-capturing capability of the numerical scheme is not adversely affected by these changes.

\subsection{Dam Break on Slope}

Modeling soil erosion from hillslopes over a rainfall event requires proper handling of the initially dry bed, the wetting of it as surface runoff begins, and the drying of it as the runoff drains away. Thus the numerical scheme used to solve the St. Venant equations should be capable of capturing wet-dry fronts accurately as well as handling wetting and drying situations. We use a simple approach to deal with dry beds, viz., by specifying a small minimum depth $h_{\min }$ and setting $q$ to zero when the minimum depth is reached.

We simulate a dam break on a $30 \mathrm{~m}$ frictionless slope $(-3 \mathrm{~m} \leq x \leq 27 \mathrm{~m})$ inclined at $5 \%$. The dam is at $x=0$ and the depth of the water behind the dam $h_{0}=0.15 \mathrm{~m}$. A similar problem was investigated by Aureli et al. (2008). The numerical solutions for $h$ and $q$ at $t=0.5 \mathrm{~s}$ and $t=6.5 \mathrm{~s}$ (Fig. 6), obtained on a 300 -cell mesh, demonstrate the stability and robustness of the numerical scheme for such scenarios. The wetting and drying fronts are plotted in Fig. 7 along with the analytical solutions, given by (Dressler, 1958) $\bar{x}_{\mathrm{wet}}=0.5(\bar{t}+2)^{2}-2$ and $\bar{x}_{\mathrm{dry}}=0.5(\bar{t}-2)^{2}-1$, where $\bar{x}=x S_{0} / h_{0}$ and $\bar{t}=t S_{0} \sqrt{g / h_{0}}$. It shows that the proposed implementation can track the wet-dry fronts well. 


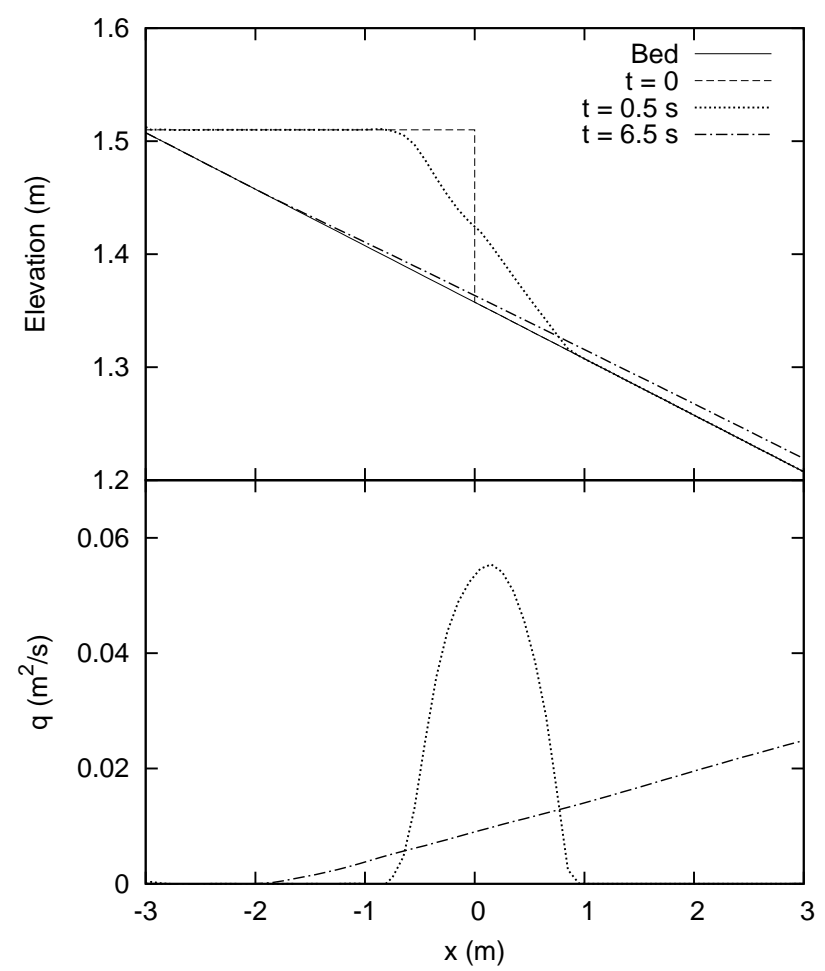

Figure 6: Numerical solution to the dam break on slope problem at different times showing the initial wetting of the slope after the dam break and subsequent drying as the water flows downslope.

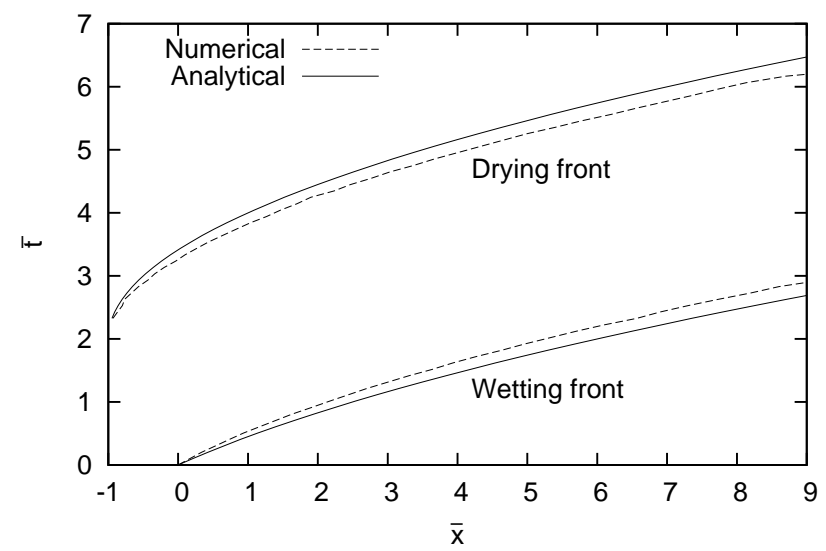

Figure 7: Numerical and analytical solutions for the wetting and drying fronts. 


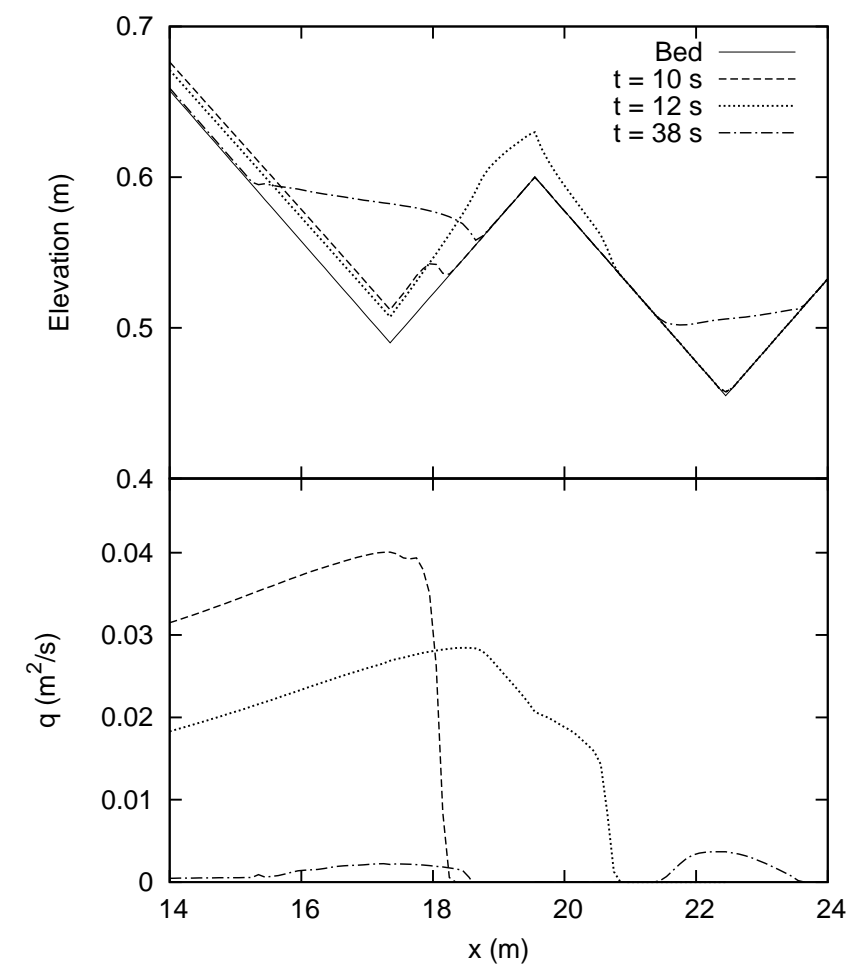

Figure 8: Numerical solutions for flow down a rough non-uniform bed. Solutions at $10 \mathrm{~s}, 12 \mathrm{~s}$ and $26 \mathrm{~s}$ show respectively (i) flow advancing up an adverse slope, (ii) flow down a favorable slope, and (iii) separation of the flow into two parts and approaching a quiescent condition in the valleys. The discharge plots demonstrate stability near the wet/dry fronts as a result of limiting the friction source term.

\subsection{Flow over Rough Non-Uniform Topography}

The friction source term $-g h S_{f}$ can cause numerical instability if not handled with care. Burguete et al. (2008) rightly identified the need to limit the friction term near wet/dry fronts, proposing the condition

$$
\left|g h S_{f}\right| \leq\left|\frac{q^{n}}{\Delta t}-g h \frac{\Delta z}{\Delta x}\right|
$$

to prevent sudden changes in the sign of $q$. They reasoned that, for flow up an adverse slope (so that $\operatorname{sgn}(q)=\operatorname{sgn}(\Delta z / \Delta x))$, the friction term can at most stop the flow and not change its direction. We suggest that this reasoning is flawed. For flow down a slope (so that $\operatorname{sgn}(q)=-\operatorname{sgn}(\Delta z / \Delta x)$ ), the above bound implies that $g h S_{f}$ may be large enough to balance $q^{n} / \Delta t-g h \Delta z / \Delta x$, which leads to the non-physical situation of the flow being stopped by friction. In reality, the bed slope source term (whether on an adverse or a favorable slope) is an unbalanced term that drives the flow. We suggest therefore that the correct bound for the friction term is

$$
\left|g h S_{f}\right| \leq\left|\frac{q^{n}}{\Delta t}\right| .
$$

To demonstrate the effectiveness of this bound, consider the initial value problem considered in the previous section but now with a rough bed and two valleys near the end of the domain. Figure 8 shows the numerical solutions obtained with $\Delta x=0.1 \mathrm{~m}$. They clearly show the numerical scheme is stable near wet/dry fronts with a reasonable modeling of the overtopping effect, separation of the flow and convergence to quiescent conditions. 


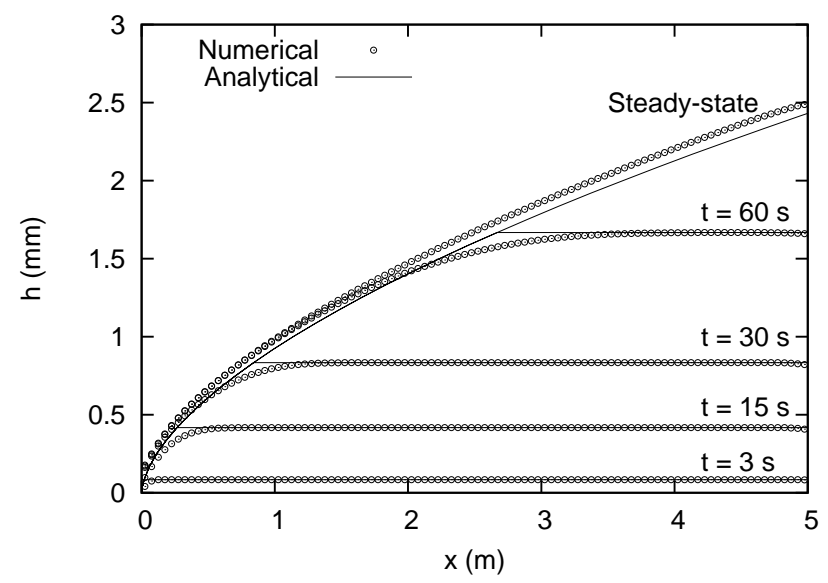

Figure 9: Comparing the numerical solution of the full St. Venant equations with the kinematic wave approximation for rainfall on uniform slope $\left(P=100 \mathrm{~mm} \mathrm{~s}^{-1}, S_{0}=0.004, n=0.02, L=5 \mathrm{~m}\right.$, $h(x, 0)=0$, and $q(0, t)=0)$.

\subsection{Rainfall on Uniform Slope}

Let us now consider the case of rainfall and overland flow on an impervious uniform slope. An analytical solution to the problem can be obtained using the kinematic wave approximation (Singh, 1996), which reduces the St. Venant equations to

$$
\begin{aligned}
\frac{\partial h}{\partial t}+\frac{\partial q}{\partial x} & =P \\
\text { where } q & =\frac{\sqrt{S_{0}}}{n} h^{5 / 3} \text { (Manning's equation). }
\end{aligned}
$$

Woolhiser and co-workers (Woolhiser and Liggett, 1967; Morris and Woolhiser, 1980) have shown that the kinematic wave model is reasonably accurate when the kinematic wave number

$$
K=\frac{S_{0} L}{h(L)\left[F_{r}(L)\right]^{2}} \geq 20
$$

and, for low Froude numbers, $\left[F_{r}(L)\right]^{2} K \geq 5$. Here $L$ is the length of the slope, $h(L)$ is the normal depth, and $F_{r}(L)$ the Froude number, at $x=L$. We can express $h(L)$ and $F_{r}(L)$ in terms of physical parameters by solving $(7)$ at steady state with $h(0)=0$. The kinematic wave number then becomes

$$
K=\frac{S_{0}^{0.4} L^{0.2} n^{1.2} g}{P^{0.8}}
$$

from which we can deduce that the kinematic wave model is a reasonable approximation to the St. Venant equations for rough, steep slopes with low rainfall intensities.

For a typical problem with $P=100 \mathrm{~mm} \mathrm{~h}^{-1}, S_{0}=0.004, n=0.02$, and $L=5 \mathrm{~m}$, the kinematic wave number works out to be $K=60.0$, with $\left[F_{R}(L)\right]^{2} K=8.23$. The kinematic wave solution to this problem at various times is shown in Fig. 9, together with the numerical solution. The numerical solution was obtained with $\Delta x=0.05 \mathrm{~m}$, a reflective boundary at $x=0$, and a transmissive one at $x=L$. The numerical steady-state solution lies slightly above the corresponding kinematic wave solution, with a maximum deviation of $0.08 \mathrm{~mm}$. This is consistent with the finding of Woolhiser and Liggett (1967).

\subsection{Rainfall-Driven Erosion}

In this section, we compare our solution of the H-R model with that obtained by Hogarth et al. (2004b) for rainfall-driven erosion. Hogarth et al. (2004b) solved the H-R model with steady flow using the finite 

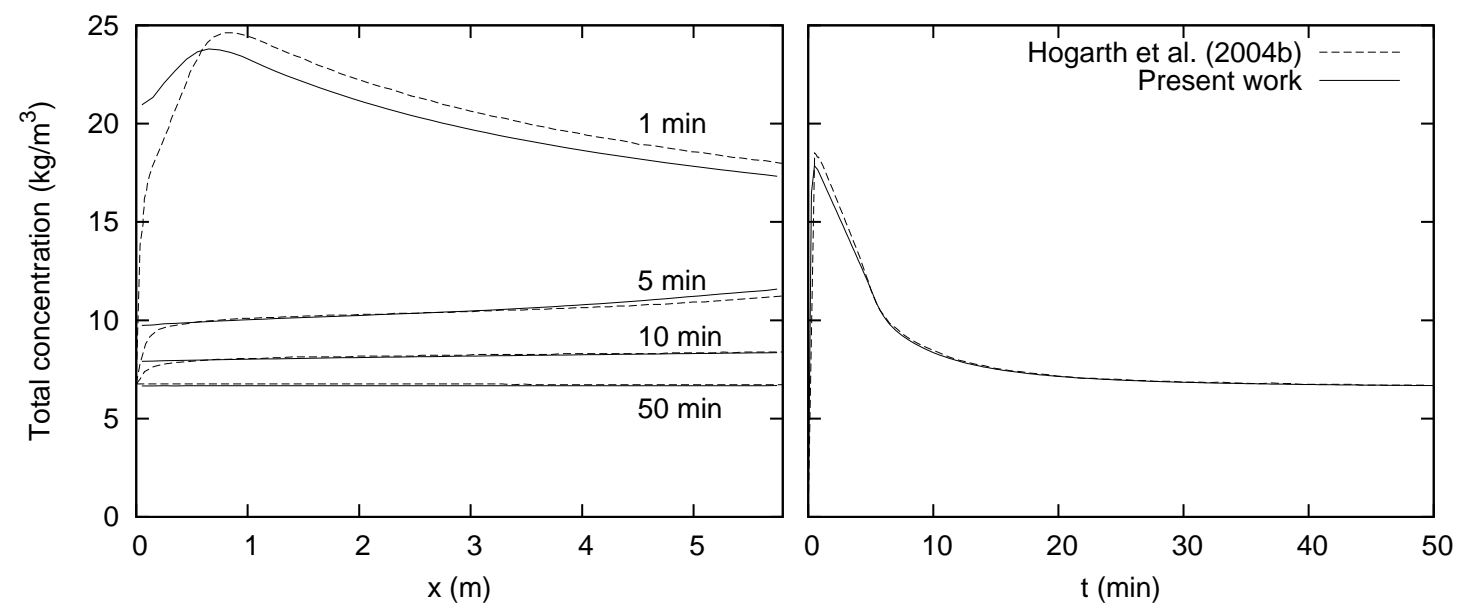

Figure 10: Comparing the numerical solutions of Hogarth et al. (2004b) and the present work for rainfall-driven erosion $\left(P=100 \mathrm{~mm} \mathrm{~s}^{-1}, S_{0}=0.004, n=0.06, L=5.8 \mathrm{~m}, a=920 \mathrm{~kg} \mathrm{~m}^{-3}\right.$, $a_{d}=14190 \mathrm{~kg} \mathrm{~m}^{-3}$, and $m_{t}=0.0767 \mathrm{~kg} \mathrm{~m}^{-2}$ ). The spatial variation of sediment concentration at various times is plotted on the left, while the temporal variation at $x=L$ is shown on the right.

difference method and obtained best-fit curves to the experimental data of Proffitt et al. (1991). Their numerical solution for one of the scenarios $\left(S_{0}=0.4 \%, n=0.06, P=100 \mathrm{~mm} \mathrm{~h}^{-1}\right.$ and settling velocity distribution $\left.v_{1, \ldots, 10}\left(\mathrm{~mm} \mathrm{~s}^{-1}\right)=0.21,0.71,3.30,10.9,19.4,31.2,69.1,139,210,300\right)$ with the best-fit parameters $a=920 \mathrm{~kg} \mathrm{~m}^{-3}, a_{d}=14190 \mathrm{~kg} \mathrm{~m}^{-3}$, and $m_{t}^{*}=0.0767 \mathrm{~kg} \mathrm{~m}^{-2}$ is shown in Fig. 10 .

We obtained a numerical solution to the same problem with $\Delta x=0.1 \mathrm{~m}$ and $\Delta t=0.003 \mathrm{~s}$. There is a good correspondence between our solution and that of Hogarth et al. (2004b) except at very early times. The discrepancy is partly due to their kinematic wave assumption. As shown in Fig. 9, the full St. Venant equations gives slightly greater flow depths than the kinematic wave model due to the backwater effect. This leads to a lower sediment concentration as the sediment mass is distributed over a greater volume of water. The difference between our solution and that of Hogarth et al. (2004b) near $x=0$ is the result of using different boundary conditions for $c_{i}$. Hogarth et al. (2004b) maintained a boundary condition of $c_{i}(0, t)=c_{i}(x, \infty)$, which they computed a priori from steady-state solutions of the H-R equations. On the other hand, we impose a reflective boundary condition at $x=0$, which maintains zero flux through the boundary but does not specify what $c_{i}(0, t)$ should be.

\subsection{Net Deposition in Overland Flow}

Beuselinck et al. (1999) conducted experiments in which sediment-laden overland flow was introduced onto a gentle slope, resulting in net deposition of sediment over the length of the flume. An analytical steady-state solution for such a scenario was subsequently developed by Sander et al. (2002) to model spatial variations in the compositions of the suspended sediment and the deposited layer. Their solution for the case where $S_{0}=0.02, n=0.01, \rho_{s}=2600 \mathrm{~kg} \mathrm{~m}^{-3}, F=0.01 \Omega_{c r}=0.186 \mathrm{~W} \mathrm{~m}^{-2}, q=$ $0.00125 \mathrm{~m}^{2} \mathrm{~s}^{-1}$, and $c_{i}(0, t)=10 \mathrm{~kg} \mathrm{~m}^{-3}$ is shown in Fig. 11. The settling velocities of the ten equal-mass sediment classes are $v_{1, \ldots, 10}\left(\mathrm{~mm} \mathrm{~s}^{-1}\right)=0.00043,0.0037,0.020,0.083,0.23,0.46,0.74,1.1$, 1.7, 3.2. The numerical solution was obtained with an 100-cell mesh and a time step of $0.1 \mathrm{~s}$. As Fig. 11 shows, the numerical and analytical solutions are virtually indistinguishable.

\section{Conclusion}

Soil erosion models founded on sound physical laws have the potential to be more generally applicable than empirical models. The H-R model is unique among physically-based models in that it considers erosion and deposition processes separately, takes into account the development of a deposited layer, and allows for multiple sediment classes. Previous - mostly analytical — work has shown that the model 


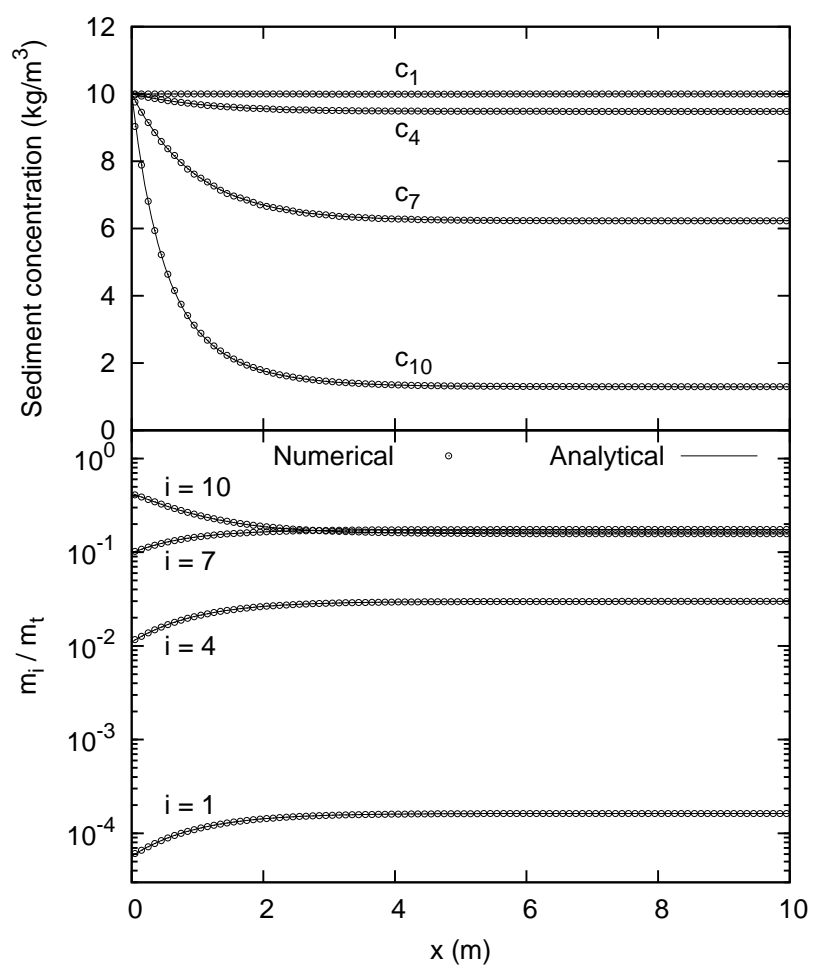

Figure 11: Numerical and analytical solutions (for selected sediment classes) for net deposition in overland flow $\left(S_{0}=0.02, n=0.01, \rho_{s}=2600 \mathrm{~kg} \mathrm{~m}^{-3}, q=0.00125 \mathrm{~m}^{2} \mathrm{~s}^{-1}, \Omega_{c r}=0.186 \mathrm{~W} \mathrm{~m}^{-2}, F=0.01\right.$, and $\left.c_{i}(0, t)=10 \mathrm{~kg} \mathrm{~m}^{-3}\right)$. 
can accurately simulate soil erosion and sediment transport under various conditions. However, the application of the model to more complex scenarios has been restricted due to the limitations of analytical solutions.

A numerical implementation of the H-R model coupled with the St. Venant equations has been presented in this paper. A well-balanced MUSCL-Hancock approach was proposed, in which

a. the flux gradient and the source terms are explicitly balanced during state reconstruction to preserve steady-state conditions in the predictor step, and

b. the quasi-cell source term integrals are decomposed into left- and right-going components for updating cell states in the corrector step.

We included in our presentation a discussion of the criteria for numerical stability when dealing with very shallow flows (such as typically encountered in soil erosion modeling), namely, a time step restriction arising from the H-R equations and a friction slope bound. The numerical scheme has been verified against a number of benchmarks and shown to be accurate and robust.

The proposed numerical scheme allows us to model a wider range of soil erosion scenarios than was previously possible. In a companion paper, we apply this scheme to various experimental and hypothetical scenarios of soil erosion to investigate the interactions between the various erosion processes and the effects of varying topography. We also take a closer look at the parameters in the H-R model.

Acknowledgments This work was supported by the Natural Environment Research Council [grant number NE/E007015/1]. We would also like to thank Professor Bill Hogarth for providing us with the settling velocity distribution for the test in Section 4.6 .

\section{References}

Aureli, F., A. Maranzoni, P. Mignosa, and C. Ziveri (2008), A weighted surface-depth gradient method for the numerical integration of the $2 \mathrm{~d}$ shallow water equations with topography, Advances in Water Resources, 31(7), 962-974, doi:http://dx.doi.org/10.1016/j.advwatres.2008.03.005.

Bermudez, A., and M. E. Vazquez (1994), Upwind methods for hyperbolic conservation laws with source terms, Computers \& Fluids, 23(8), 1049-1071, doi:http://dx.doi.org/10.1016/0045-7930(94)90004-3.

Beuselinck, L., G. Govers, A. Steegen, and T. A. Quine (1999), Sediment transport by overland flow over an area of net deposition, Hydrological Processes, 13(17), 2769-2782, doi: http://dx.doi.org/10.1002/(SICI)1099-1085(19991215)13:17\%3C2769::AID-HYP898\%3E3.0.CO;2-X.

Beuselinck, L., P. B. Hairsine, G. C. Sander, and G. Govers (2002), Evaluating a multiclass net deposition equation in overland flow conditions, Water Resources Research, 38(7), 1109+, doi: http://dx.doi.org/10.1029/2001WR000250.

Burguete, J., P. García-Navarro, and J. Murillo (2008), Friction term discretization and limitation to preserve stability and conservation in the 1d shallow-water model: Application to unsteady irrigation and river flow, International Journal for Numerical Methods in Fluids, 58(4), 403-425, doi: http://dx.doi.org/10.1002/fld.1727.

Courant, R., K. Friedrichs, and H. Lewy (1967), On the partial differential equations of mathematical physics, IBM Journal, 11, 215-234.

Dressler, R. F. (1958), Unsteady non-linear waves in sloping channels, Proceedings of the Royal Society of London. Series A, Mathematical and Physical Sciences (1934-1990), 247(1249), 186-198, doi:http://dx.doi.org/10.1098/rspa.1958.0177.

George, D. L. (2008), Augmented riemann solvers for the shallow water equations over variable topography with steady states and inundation, Journal of Computational Physics, 227(6), 3089-3113, doi:http://dx.doi.org/10.1016/j.jcp.2007.10.027. 
Goutal, N., and F. Maurel (1997), Proceedings of the 2nd workshop on dam-break wave simulation, Tech. rep., Groupe Hydraulique Fluviale, Département Laboratoire National dHydraulique, Electricité de France.

Hairsine, P. B., and C. W. Rose (1991), Rainfall detachment and deposition: Sediment transport in the absence of flow-driven processes, Soil Sci Soc Am J, 55(2), 320-324.

Hairsine, P. B., and C. W. Rose (1992a), Modeling water erosion due to overland flow using physical principles, 1, sheet flow, Water Resources Research, 28(1), 237-243.

Hairsine, P. B., and C. W. Rose (1992b), Modeling water erosion due to overland flow using physical principles, 2, rill flow, Water Resources Research, 28(1), 245-250.

Hairsine, P. B., G. C. Sander, C. W. Rose, Parlange, W. L. Hogarth, I. Lisle, and H. Rouhipour (1999), Unsteady soil erosion due to rainfall impact: a model of sediment sorting on the hillslope, Journal of Hydrology, 220(3-4), 115-128, doi:http://dx.doi.org/10.1016/S0022-1694(99)00068-2.

Hairsine, P. B., L. Beuselinck, and G. C. Sander (2002), Sediment transport through an area of net deposition, Water Resources Research, 38(6), 1086+, doi:http://dx.doi.org/10.1029/2001WR000265.

Harten, A., and J. Hyman (1983), Self adjusting grid methods for one-dimensional hyperbolic conservation laws, Journal of Computational Physics, 50(2), 235-269, doi:http://dx.doi.org/10.1016/00219991(83)90066-9.

Hogarth, W. L., Parlange, C. W. Rose, G. C. Sander, T. S. Steenhuis, and A. Barry (2004a), Soil erosion due to rainfall impact with inflow: an analytical solution with spatial and temporal effects, Journal of Hydrology, 295(1-4), 140-148, doi:http://dx.doi.org/10.1016/j.jhydrol.2004.03.007.

Hogarth, W. L., C. W. Rose, J. Y. Parlange, G. C. Sander, and G. Carey (2004b), Soil erosion due to rainfall impact with no inflow: a numerical solution with spatial and temporal effects of sediment settling velocity characteristics, Journal of Hydrology, 294(4), 229-240, doi: http://dx.doi.org/10.1016/j.jhydrol.2004.02.014.

Hubbard, M. E., and P. Garcia-Navarro (2000), Flux difference splitting and the balancing of source terms and flux gradients, Journal of Computational Physics, 165(1), 89-125.

LeVeque, R. J. (1998), Balancing source terms and flux gradients in high-resolution godunov methods: The quasi-steady wave-propagation algorithm, Journal of Computational Physics, 146(1), 346-365, doi:http://dx.doi.org/10.1006/jcph.1998.6058.

Li, J., and G. Chen (2006), The generalized riemann problem method for the shallow water equations with bottom topography, International Journal for Numerical Methods in Engineering, 65(6), 834-862, doi:http://dx.doi.org/10.1002/nme.1471.

Meerveld, T.-V. H. J., J. Y. Parlange, D. A. Barry, M. F. Tromp, G. C. Sander, M. T. Walter, and M. B. Parlange (2008), Influence of sediment settling velocity on mechanistic soil erosion modeling, Water Resources Research, 44, W06,401+, doi:http://dx.doi.org/10.1029/2007WR006361.

Morris, E. M., and D. A. Woolhiser (1980), Unsteady one-dimensional flow over a plane: Partial equilibrium and recession hydrographs, Water Resources Research, 16(2), 355-360.

Murillo, J., P. García-Navarro, P. Brufau, and J. Burguete (2008), 2d modelling of erosion/deposition processes with suspended load using upwind finite volumes, Journal of Hydraulic Research, 46(1), 99-112.

Noelle, S., Y. Xing, and C. Shu (2007), High-order well-balanced finite volume weno schemes for shallow water equation with moving water, Journal of Computational Physics, 226(1), 29-58, doi: http://dx.doi.org/10.1016/j.jcp.2007.03.031.

Nord, G., and M. Esteves (2005), Psem_2d: A physically based model of erosion processes at the plot scale, Water Resources Research, 41, W08,407+, doi:http://dx.doi.org/10.1029/2004WR003690. 
Parlange, W. L. Hogarth, C. W. Rose, G. C. Sander, P. Hairsine, and I. Lisle (1999), Addendum to unsteady soil erosion model, Journal of Hydrology, 217(1-2), 149-156, doi: http://dx.doi.org/10.1016/S0022-1694(99)00012-8.

Proffitt, A. P. B., C. W. Rose, and P. B. Hairsine (1991), Rainfall detachment and deposition: Experiments with low slopes and significant water depths, Soil Sci Soc Am J, 55(2), 325-332.

Quirk, J. (1994), An alternative to unstructured grids for computing gas dynamic flows around arbitrarily complex two-dimensional bodies, Computers \& Fluids, 23(1), 125-142, doi: http://dx.doi.org/10.1016/0045-7930(94)90031-0.

Roe, P. L. (1981), Approximate riemann solvers, parameter vectors, and difference schemes, Journal of Computational Physics, 43(2), 357-372, doi:http://dx.doi.org/10.1016/0021-9991(81)90128-5.

Rose, C. W., B. Yu, W. L. Hogarth, A. E. Okom, and H. Ghadiri (2003), Sediment deposition from flow at low gradients into a buffer strip-a critical test of re-entrainment theory, Journal of Hydrology, 280(1-4), 33-51, doi:http://dx.doi.org/10.1016/S0022-1694(03)00184-7.

Rose, C. W., B. Yu, H. Ghadiri, H. Asadi, J. Y. Parlange, W. L. Hogarth, and J. Hussein (2007), Dynamic erosion of soil in steady sheet flow, Journal of Hydrology, 333(2-4), 449-458, doi: http://dx.doi.org/10.1016/j.jhydrol.2006.09.016.

Sander, G. C., P. B. Hairsine, C. W. Rose, D. Cassidy, Parlange, W. L. Hogarth, and I. G. Lisle (1996), Unsteady soil erosion model, analytical solutions and comparison with experimental results, Journal of Hydrology, 178(1-4), 351-367, doi:http://dx.doi.org/10.1016/0022-1694(95)02810-2.

Sander, G. C., P. B. Hairsine, L. Beuselinck, and G. Govers (2002), Steady state sediment transport through an area of net deposition: Multisize class solutions, Water Resources Research, 38(6), 1087+, doi:http://dx.doi.org/10.1029/2001WR000323.

Sander, G. C., J. Y. Parlange, D. A. Barry, M. B. Parlange, and W. L. Hogarth (2007a), Limitation of the transport capacity approach in sediment transport modeling, Water Resources Research, 43, W02,403+, doi:http://dx.doi.org/10.1029/2006WR005177.

Sander, G. C., T. Zheng, and C. W. Rose (2007b), Update to modeling water erosion due to overland flow using physical principles: 1. sheet flow, Water Resources Research, 43(4), W04,408+, doi: http://dx.doi.org/10.1029/2006WR005601.

Simpson, G., and S. Castelltort (2006), Coupled model of surface water flow, sediment transport and morphological evolution, Computers \& Geosciences, 32(10), 1600-1614, doi: http://dx.doi.org/10.1016/j.cageo.2006.02.020.

Singh, V. P. (1996), Kinematic Wave Modeling in Water Resources: Surface-water Hydrology, John Wiley, New York.

van Leer, B. (1979), Towards the ultimate conservative difference scheme. $\mathrm{v}$ - a second-order sequel to godunov's method, Journal of Computational Physics, 32, 101-136, doi:http://dx.doi.org/10.1016/00219991(79)90145-1.

van Leer, B. (1984), On the relation between the upwind-differencing schemes of godunov, engquist-osher and roe, SIAM Journal on Scientific and Statistical Computing, 5(1), 1-20.

Van Oost, K., L. Beuselinck, P. B. Hairsine, and G. Govers (2004), Spatial evaluation of a multi-class sediment transport and deposition model, Earth Surface Processes and Landforms, 29(8), 1027-1044, doi:http://dx.doi.org/10.1002/esp.1089.

Woolhiser, D. A., and J. A. Liggett (1967), Unsteady, one-dimensional flow over a planethe rising hydrograph, Water Resources Research, 3(3), 753-771.

Zhou, J. G., D. M. Causon, C. G. Mingham, and D. M. Ingram (2001), The surface gradient method for the treatment of source terms in the shallow-water equations, Journal of Computational Physics, $168(1), 1-25$. 